\title{
A novel ion selective PVC membrane electrode for determination of propranolol in pharmaceutical formulation
}

\author{
H.Y. Aboul-Enein ${ }^{1 *}$ and Xian Xiang Sun ${ }^{2}$ \\ ${ }^{1}$ Pharmaceutical Analysis Laboratory, Biological \& Medical Research Department (MBC-03), \\ King Faisal Specialist Hospital \& Research Centre, P.O. Box 3354, Riyadh 11211, Saudi Arabia \\ ${ }^{2}$ Department of Chemical Technology, Jiangsu Institute of Petrochemical Technology, \\ Changzhou, 213016, P.R. China
}

\begin{abstract}
A novel ion selective PVC membrane electrode for determination of propranolol is developed. Silicotungstic acid is used as the counter ion and diisononyl phthalate (DNP) used as the plastizer. The electrode exhibits excellent potential response properties, showing a Nernstian response in the concentration of $3.0 \times 10^{-6} \sim 2.6 \times 10^{-2} \mathrm{M}$ with the slope of $54.7 \mathrm{mV}$ per decade, shorter conditioning time $(\sim 3 \mathrm{~h})$, fast response time $(40 \mathrm{~s})$, a lower limit of detection $\left(1.0 \times 10^{-7} \mathrm{M}\right)$. The electrode is successfully used for the analysis of propranolol in pharmaceutical formulation with the recoveries of $99.2 \sim 102.6 \%$, by using a direct potentiometric method and which does not require tedious sample preparation.
\end{abstract}

Keywords. Propranolol - ion-selective electrode - potentiometry - analysis of drugs - pharmaceutical analysis chemical sensors.

\section{Introduction}

Propranolol hydrochloride, 1-(isopropylamino)-3-(1-napthyloxy)-2-propanol hydrochloride, is a beta-adrenergic receptor blocking agent that is prescribed for its antihypertensive, antianxiety, anticovulsant and antianginal effects. In some pharmacopoeia, propranolol hydrochloride is analyzed by titrimetrical method in non-aqueous media [1] (non-aqueous acidimetric method), spectrophotometric method [1-2], and high-performance liquid chromatographic method (HPLC) [2]. Numerous methods for the determination of propranolol hydrochloride in pharmaceutical formulation has been proposed in the literature, such as colorimetry and, spectrophotometry [3-7], phosphorimetry [8], HPLC [9-11], kinetic determination [12], a.c. oscillopolarographic titration [13] and conductometry [14]. In the non-aqueous titration method (acidimetric method), because of the small $\mathrm{pH}$ ranges which usually take place as the titration ends, it is difficult to apply this method for the determination of lower concentration range of the drug in the pharmaceutical preparations. Colored and turbid solutions interfere with the measurement of the absorbance in spectrophotometric method. Tedious sample preparation is often required in the chromatographic methods. Ion-selective electrodes (ISEs) or sensors have been considered as an attractive technique in the analysis of drugs due to the larger concentration range of analyte determined, reasonable selectivity, simple procedures which require no prior separation or sample preparation, and the accuracy of the analytical information $[15,16]$. For the determination of propranolol using ion-selective electrodes in pharmaceutical preparations, Zhang and co-workers [17] described the propranolol ion selective PVC membrane electrode in which the electroactive compounds or ion-pair complexes, propranolol-dinonyl naphalenesulphonate (DNNS) or propranolol-tetra(2-chloro-phenyl) borate (CITPB), in the membrane, were obtained in situ by soaking DNNS/PVC or CITPB/PVC membranes in the propranolol solution. However, the long conditioning soaking time $(24 \mathrm{~h})$ of the electrode was required and a higher detection limit of $2.5 \sim 4.0 \times 10^{-6} \mathrm{M}$ of propranolol was reported. In this paper, the development of a novel propranolol ion-selective PVC membrane electrode is described. The electrode is successfully applied to analysis of propranolol hydrochloride in pharmaceutical formulation.

\section{Experimental section}

\section{Reagents and materials}

Propranolol hydrochloride was obtained in the pure raw material and in tablet dosage formulations from Changzhou Pharmaceutical Chemicals Works (Jiangsu, China). All reagents and solvents were of analytical reagent grade and deionized water was used throughout. 


\section{Original articles}

Standard solutions of propranolol hydrochloride were prepared by successive dilution of a $0.1 \mathrm{M}$ stock solution which was obtained by dissolving $1.479 \mathrm{~g}$ propranolol hydrochloride in $50 \mathrm{~mL}$ of water.

\section{Preparation of the electroactive materials}

The propranolol-silicotungstate was used as the electroactive material in the membrane. It was prepared by dissolving $0.88 \mathrm{~g}$ of silicotungstic acid in $30 \mathrm{~mL}$ water and mixing the solution of silicotungtic acid and $20 \mathrm{~mL}$ of $0.01 \mathrm{M}$ propranolol hydrochloride solution. The resulting precipitate was filtered out on a porosity sintered-glass crucible (G4), washed with water and dried at $50{ }^{\circ} \mathrm{C}$. The other electroactive component, propranolol-tetraphenylborate, was prepared in a similar way.

\section{Preparation of the electrode}

The mixture of the PVC cocktail was prepared by dissolving $4 \mathrm{mg}$ of the propranolol- silicotungstate, $255 \mathrm{mg}$ of high molecular weigh poly (vinyl chloride) (PVC), $141 \mathrm{mg}$ of DNP in $2 \mathrm{~mL}$ of tetrahydrofuran, the membrane was prepared by pouring the mixture onto a glass petri dish (ca. $4 \mathrm{~cm}$ diameter) and allowed to stand overnight to dry at room temperature.

The PVC membrane electrode was fabricated using procedures that were previously described [18]. The $\mathrm{Ag}-\mathrm{AgCl}$ electrode and $1.0 \times 10^{-3} \mathrm{M}$ of propranolol solution were used as the reference electrode and the internal filling solution of the electrode, respectively. (The assembled electrode denoted as the electrode A). The other PVC membrane electrode (denoted as the electrode B), based on propranololtetraphenylborate used as the electroactive material and dibutyl phthalate (DBP) as the plasticizer (the PVC membrane compositions was 1.0:35.3:63.7 electroactive material: PVC: DBP respectively), was also assembled in a similar way.

The assembled electrodes were conditioned by soaking into $1.0 \times 10^{-3} \mathrm{M}$ of propranolol hydrochloride solution for $3 \mathrm{~h}$ before the use of electrodes. When not in use, the electrodes were stored in air.

\section{Measurement of electromotive force (emf)}

The emf measurements were carried out at room temperature with a PXG-IB digital $\mathrm{pH} / \mathrm{mV}$ meter (Jiangsu
Electroanalytical Instrument Factory). A propranolol selective PVC membrane electrode and a saturated calomel electrode (model 231) were used as indicating electrode and the reference electrode respectively. The test solutions were constantly stirred by a magnetic stirrer. The electrochemical cell was as follows:

S.C.E. / test solution / ISE.

\section{Analytical method for pharmaceutical formulations}

Not less than 10 propranolol hydrochloride tablets were weighed accurately crushed and mixed in a mortar. The sample solution was prepared as follows: a portion of the powder equivalent to $10 \mathrm{mg}$ of propranolol hydrochloride was accurately weighed, and dissolved in $30 \mathrm{~mL}$ of water under stirring or sonicating condition. The resulting solution was transferred into a $50 \mathrm{ml}$ volumetric flask, $5 \mathrm{ml}$ of $\mathrm{pH} 5.5$ acetate buffer solution was added, then completed to volume with water. The sample solution was transferred to a $100 \mathrm{ml}$ breaker. The propranolol ion-selective membrane electrode and the reference electrode were immersed into the test solution. The emf reading was recorded. The amount of propranolol hydrochloride tablet was determined by using the calibration curve method.

\section{Results and discussion}

\section{Response characteristics of the electrodes}

The performances of the electrodes prepared with one of two ion-pair complexes, propranolol silicotungstate (electrode A) and propranolol tetraphenylborate (electrode B), as the electroactive materials in the membrane were experimentally compared. The results and the calibration graphs obtained with the two electrodes are shown in table I and figure 1.

From table I and figure 1, it is obvious that electrode A exhibits an excellent potential response properties such as the linearity range of $2.6 \times 10^{-2} \sim 3.0 \times 10^{-6} \mathrm{M}$ and detection limit of $1.0 \times 10^{-} \mathrm{M}$ of propranolol hydrochloride and is performing much better, over one order of magnitude better than both electrode $\mathrm{B}$ and the electrodes based on fabrication with the use of either dinonylnaphthalene sulphonic acid or tetra (2-chlorophenyl) borate (potassium salt) as an electroactive site carrier in the membrane.

Table I. Response characteristics of the electrodes.

\begin{tabular}{lcc}
\hline Parameter & Electrode A & Electrode B \\
\hline Slope (mV per decade) & 54.7 & 53.7 \\
Linearity range (M) & $2.6 \times 10^{-2}-3.0 \times 10^{-6}$ & $1.0 \times 10^{-1}-3.5 \times 10^{-5}$ \\
Detection limit (M) & $1.0 \times 10^{-7}$ & $1.0 \times 10^{-6}$ \\
Equation & $Y=54.72 x+293.1$ & $Y=53.66 x+312.2$ \\
Correlation coefficient & 0.9999 & 0.9964 \\
\hline
\end{tabular}




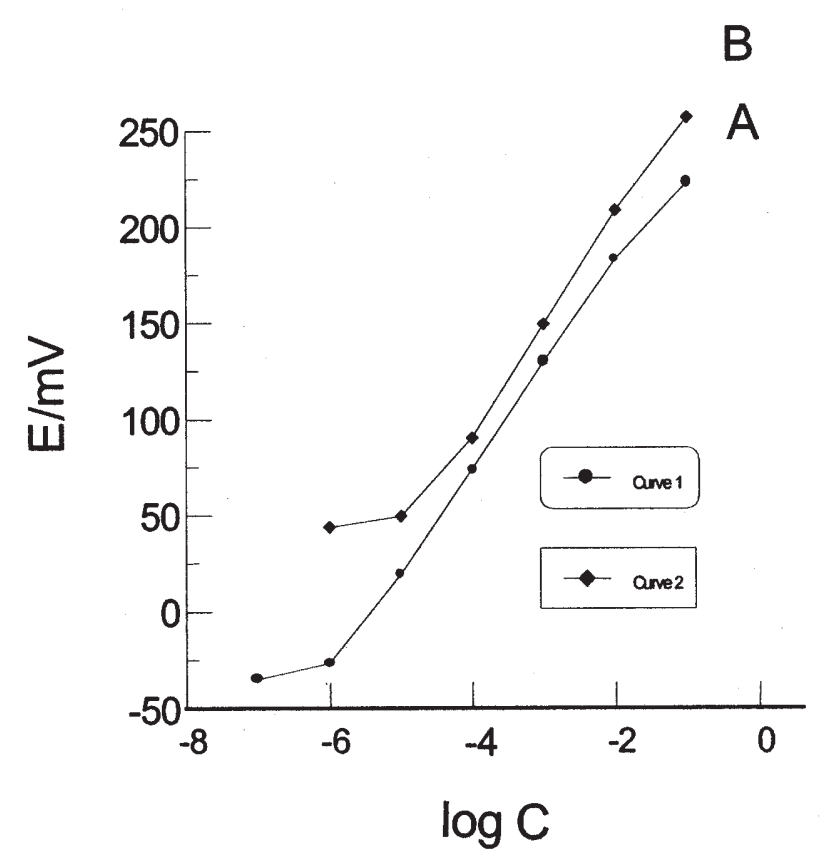

Figure 1. Calibration curves for the two electrodes selective to propranolol: Electrode A (O); Electrode B (ם).

\section{Effect of $\mathrm{pH}$}

The effect of $\mathrm{pH}$ of the test solution $\left(1.0 \times 10^{-3} \mathrm{M}\right.$ propranolol) on the response of the electrode was examined by measuring the variation in the emf with change in $\mathrm{pH}$ produced by the addition of very small volume of $0.01 \sim 0.1 \mathrm{M}$ sodium hydroxide or hydrochloric acid solution into the test solution. Figure 2 showed that at a $\mathrm{pH}$ range of $2.5 \sim 8.0$ and $4.0 \sim 7.5$ for $10^{-3} \mathrm{M}$ and $10^{-4} \mathrm{M}$ propranolol solutions, respectively, no significant effect on the electrode potential were observed. At lower $\mathrm{pH}$ values $(\mathrm{pH} 4.0)$ the potential increased with decrease in the $\mathrm{pH}$, presumably the electrode being sensitive to the diprotonated species. At higher $\mathrm{pH}$ values $(\mathrm{pH} 7.5)$ the potential decreased due to the precipitation of propranolol base [17]. Therefore, the electrode can be used at $\mathrm{pH}$ of $4.0 \sim 7.5$ for propranolol determination.

\section{Response time, stability and reproducibility}

The response time of the electrode $\mathrm{A}$ was tested at $1.0 \times 10^{-1} \sim 1.0 \times 10^{-6} \mathrm{M}$ of propranolol solutions and response time were about $5 \mathrm{~s}$ for $1.0 \times 10^{-3} \mathrm{M}$ of propranolol solution and about $40 \mathrm{~s}$ for $1.0 \times 10^{-3} \mathrm{M}$ of propranolol solution. The stability of the electrode response was monitored continuously at $1.0 \times 10^{-4} \mathrm{M}$ of propranolol solution and evaluated for a period of $6 \mathrm{~h}$; the potential drift was $<0.2 \mathrm{mV} / \mathrm{h}$.

The repeatability of the potential reading for the electrode was examined by subsequent measurements in $1.0 \times 10^{-2} \mathrm{M}$ of propranolol solution immediately after measuring the first

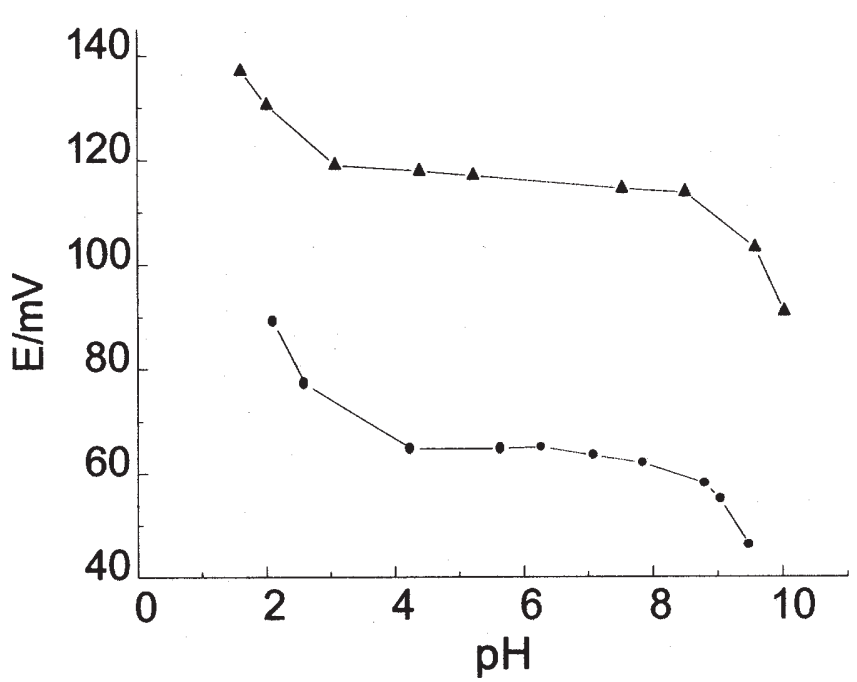

Figure 2. Effect of $\mathrm{pH}$ on the potential of the electrode A. Propranolol concentration $1 \times 10^{-4} \mathrm{M}(\mathbf{\bullet})$ and $1 \times 10^{-3} \mathrm{M}(\mathbf{\Delta})$.

set of solution at $1.0 \times 10^{-4} \mathrm{M}$ of propranolol solution. The relative standard deviations for 6 replicate measurements obtained are $0.12 \%$ for the solution of $1.0 \times 10^{-2} \mathrm{M}$ and $0.23 \%$ for the solution of $1.0 \times 10^{-4} \mathrm{M}$ respectively. The electrodes were used at least for three months for serial calibrations and analytical applications.

\section{Selectivity of the electrode}

The selectivity of the electrode A was investigated by the separate solution method and calculated from the equation:

$$
\log K_{\mathrm{PRO}^{+}, Z_{j}}^{\mathrm{pot}}=\frac{E_{j}-E_{1}}{S}+1-\left(\frac{1}{Z_{j}}\right) \log \left[\mathrm{PRO}^{+}\right]
$$

where $J^{Z j+}$ is the interfering ion, $Z_{j}$ is the charge of the interfering ion; $E_{j}$ and $E_{1}$ are the electrode potential $1.0 \times 10^{-3} \mathrm{M}$ solution of the primary ion $\left(\mathrm{PRO}^{+}\right)$and $J^{\mathrm{Zj+}}$, respectively, $S$ is the slope of the calibration graph for the $\mathrm{PRO}^{+}$ion.

The potentiometric selectivity coefficients summarized in table II, show that all the inorganic compounds and most of the drugs, including metoprolol, do not affect the electrode behavior except for chlorphenamine and chlorpromazine. However, these two drugs are never associated with propranolol hydrochloride in pharmaceutical formulations. Accordingly, they do not influence the propranolol determination. Excipients in the propranolol tablets such as cornstarch, sugar, gelatin and magnesium stearate do not interfere.

\section{Application to drug analysis}

The reliability of the proposed propranolol-selective PVC membrane electrode for the quantification of propranolol 


\section{Original articles}

Table II. Selectivity Coefficients of the Electrode.

\begin{tabular}{lc}
\hline Interfering species $(j)$ & $K_{\text {propranolol, } ;}^{\text {pot }}$ \\
\hline $\mathrm{KCl}$ & $5.6 \times 10^{-3}$ \\
$\mathrm{NaAc}$ & $3.2 \times 10^{-3}$ \\
$\mathrm{NH}_{4} \mathrm{Cl}$ & $1.1 \times 10^{-2}$ \\
$\mathrm{CaCl}_{2}$ & $3.3 \times 10^{-4}$ \\
$\mathrm{MgSO}_{4}$ & $2.2 \times 10^{-4}$ \\
$\mathrm{Caffeine}$ & $3.5 \times 10^{-3}$ \\
Urea & $2.0 \times 10^{-3}$ \\
Salbutamol sulfate & $1.2 \times 10^{-2}$ \\
Vitamin $\mathrm{B}_{6}$ & $2.3 \times 10^{-2}$ \\
Metoprolol tartrate & $5.8 \times 10^{-2}$ \\
Ephedrine hydrochloride & $2.1 \times 10^{-2}$ \\
Chlorphenamine & 2.6 \\
Chlorpromazine & 69.2 \\
\hline
\end{tabular}

Table III. Recovery of propranolol hydrochloride.

\begin{tabular}{lcc}
\hline Added & Found $^{a} / \mathrm{mg}$ & Recovery $^{b} / \%$ \\
\hline 2.96 & 3.02 & $102.1 \pm 1.7$ \\
11.83 & 11.98 & $101.3 \pm 2.1$ \\
29.58 & 30.35 & $102.6 \pm 1.6$ \\
\hline
\end{tabular}

${ }^{a}$ Average of five determinations.

${ }^{\mathrm{b}}$ Recovery \pm standard deviation.

was assessed by determining $2.0 \times 10^{-4} \sim 2.0 \times 10^{-3} \mathrm{M}$ propranolol solution using the direct potential method. The recovery is shown in table III. In all cases the relative standard deviations were $2.2 \%$. The mean of recovery and the mean standard deviation were $102.0 \%$ and $1.8 \%$, respectively.

The direct potential method was applied to the determination of propranolol hydrochloride in pharmaceutical tablets (ca. $10 \mathrm{mg}$ propranolol hydrochloride/tablet, Changzhou pharmaceutical chemical works, batch number: 980506) and compared with the pharmacopoeia method (spectrophotometric method [2]). The mean value and the relative standard deviation obtained by using propranololselective membrane electrode method was $9.43 \mathrm{mg} / \mathrm{tablet}$ and $1.9 \%(n=6)$ respectively. This is in good agreement with the value of $9.50 \mathrm{mg} /$ tablet obtained by using spectrophotometric method.

\section{Conclusion}

The electrode prepared with the ion pair complex of propranolol-silicotungstate as the electroactive material in the membrane has been successfully applied to the determination of propranolol hydrochloride in pharmaceutical formulations. The proposed method possesses many advantages such as fast response, lower detection of limit $\left(<10^{-6} \mathrm{M}\right)$, good accuracy, adequate selectivity in the presence of related species and simple analytical procedures for the determination of propranolol hydrochloride in tablet formulation without the need for any sample preparation.

\section{Acknowledgement}

One of the authors (HYA-E) wishes to thank the Administration of King Faisal Specialist Hospital and Research Centre for its continuous support of the Pharmaceutical Analysis Laboratory.

\section{References}

1. Commission of the Ministry of Health Chinese Pharmacopoeia; Beijing, 1995, pp 710-711.

2. U.S. Pharmacopoeia; The United States Pharmacopoeia Convention Inc., Rockville, MD, 1995, 23rd. ed., pp 13281330.

3. Erran, S.V.; Tipnis, H. P. Indian Drugs 1994, 31, 65-68.

4. Sastry, C.S.P.; Srinivas, K.R.; Krihna Prasad, M.M. Mikrochim. Acta 1996, 122, 77-86.

5. Prasad, C.V.N.; Bharadwaj, V.; Narsimhan, V.; Chowdhary, R.T.; Parimoo, P. J. AOAC. Int. 1997, 80, 325-330.

6 Husain,S.; Krishnamurthy, A.S.R. Indian Drugs 1995, 32, 574577.

7. Chen, Z.S.; Cai, J.A.; Liang, M.L. Yaowu Fenxi Zazhi 1996, 16, 195-197.

8. Rapodo Martinez, I.; Villanueva Camanas, R.M.; GarciaAlvarez-Coque, M.C. Analyst 1994, 119, 1093-1097.

9. Olsen, C.S.; Croggins, H.S. J. Assoc. Off. Anal Chem. 1998, 71, 761-763.

10. Hitscherich, M.E.; Rydberg, E.M.; Tsilifonis, D.C.; Daly, R.E. J. Liq. Chromatogr. 1987, 10, 1011-1021.

11. Galeano Diaz, T.; Salinas, F.; Guberteau Cabanillos, C. Ann. Chim. (Rome) 1993, 81, 523-528.

12. Sultan, S.M. Analyst 1988, 113, 149-152.

13. Cui, Z. Yaowu Fenxi Zazhi 1991, 11, 41-42.

14. Issa, Y.M.; Amin, A.S. Mikrochim. Acta 1995, 118, 85-89.

15. Hassan, S.S.; Amer, M.M.; Abd El-Fatah, S.A.; El-Kosasy, A.M. Anal. Chim. Acta 1998, 363, 81-87.

16. Stefan, R.I.; Baiulescu, G.E.; Aboul-Enein, H.Y. Crit. Rev. in Anal. Chem. 1997, 24, 307-321.

17. Zhang, Z.R.; Mao, D.Y.; Li, Y.X. and Cosofret, V.V. Talanta 1990, 37, 673-676.

18. Sun, X.X.; Ding, H.L. Fenxi ShiYan Shi 1999, 18, 75-79. 